\title{
Assessment of Lifetime Ocular Exposure to UV-B: The Melbourne Visual Impairment Project
}

\author{
Catherine A. McCarty, Sharon E. Lee, Patricia M. Livingston, \\ Hugh R. Taylor \\ Department of Ophthalmology, University of Melbourne, Royal Victorian Eye and \\ Ear Hospital, Melbourne, Vic., Australia
}

Recent reviews of the published literature revealed conflicting evidence for an association between solar ultraviolet radiation and ocular diseases such as cataract, climatic droplet keratopathy, uveal melanoma and macular degeneration [1,2]. Differences between study conclusions could be due to methodology, and in some cases, the 'ecological fallacy' [3]. The ecological fallacy occurs when conclusions regarding individual risk (i.e. of cataract) are inferred based on data collected regarding group risk. To avoid the ecological fallacy, it is necessary to collect individual exposure data.

Individual ocular UV-B exposure is dependent on four factors which must all be assessed to avoid the ecological fallacy: (1) the ambient level of UV-B in the environment; (2) the amount of time the individual spends outdoors and is exposed to UV-B radiation; (3) the ocular ambient exposure ratio (the proportion of ambient UV-B that actually reaches the eye), and (4) the use of ocular protection such as hats and sunglasses [4]. The aim of this study was to develop a questionnaire and model for use in epidemiologic studies to quantify lifetime personal ocular UV-B exposure.

\section{Methods}

Questionnaire

The model to quantify lifetime ocular exposure to UV-B requires the collection of personal exposure information. For the period of time that a person was in school, the only information collected was the place of residence, assuming that personal behaviour did not

\section{Reprint}

Publishers: S.Karger, Basel

Printed in Switzerland 
vary greatly between children and that latitude was the primary determinant of ocular UVB exposure.

For the adult life periods, people were asked to recall their UV-related behaviour for the summer months only. This period restriction greatly reduced the time required to administer the questionnaire. In the Chesapeake Bay Waterman Study, it was shown that $96 \%$ of the total cumulative UV-B exposure was explained by the summer cumulative UV-B exposure and that this relationship did not vary by age [5]. It was assumed that this relationship was true for other populations also.

For each life period greater than 6 months, participants were asked how many hours they spent outdoors between 9 a.m. and 5 p.m. daylight savings time during the summer months on work days and weekend days, assuming 2 weekend days. They were then asked the proportion of time while outdoors that they wore a hat, sunglasses, glasses or contact lenses and the proportion of outdoor time that was spent over water. Any change in ocular protection behaviour signalled a new life period to be entered on the questionnaire.

\section{Personal Ocular UV-B Exposure Model}

The model to quantify lifetime personal effective ocular exposure from the information collected with the questionnaire is based on research conducted for the Chesapeake Bay Waterman Study [6-10]. Attenuation factors for use of hat, sunglasses, glasses, contact lenses and for activities conducted over water are included in the model together with the amount of time spent outdoors. The location factor is relative to Melbourne, Australia, and the final units quantified are 'Melbourne sun years'.

\section{Evaluation in the Melbourne Visual Impairment Project}

The questionnaire and model were employed in the Melbourne Visual Impairment Project, a population-based study of the distribution and determinants of eye disease in a random selection of the population aged 40 years and older [11]. A household census was conducted in each of nine randomly selected pairs of census collector districts to determine the eligibility of household residents. Eligible residents were invited to attend a local screening centre and left with a brief 'homework' sheet to complete prior to their visit to the test site. On this sheet, they were asked to record their occupations and places of residence for their entire lifetime. This reduced the time taken to complete administration of the sunlight questionnaire at the local test site. The questionnaire took an average of $12 \mathrm{~min}$ to administer, ranging from 3 to 25 min depending on the age and residential mobility of the participant.

\section{Results}

A final response rate of $83 \%$ was achieved upon the assessment of 3,271 individuals. They ranged in age from 40 to 98 years (mean 59) and 54\% were female.

The range of lifetime ocular UV-B exposure was from 0.01 to 3.64 Melbourne sun years and varied significantly by gender $\left(\chi^{2}=248.9, \mathrm{p}<0.001\right)$ (fig. 1). The distribution for both genders is skewed to the left, with relatively few people having extremely high exposures. 


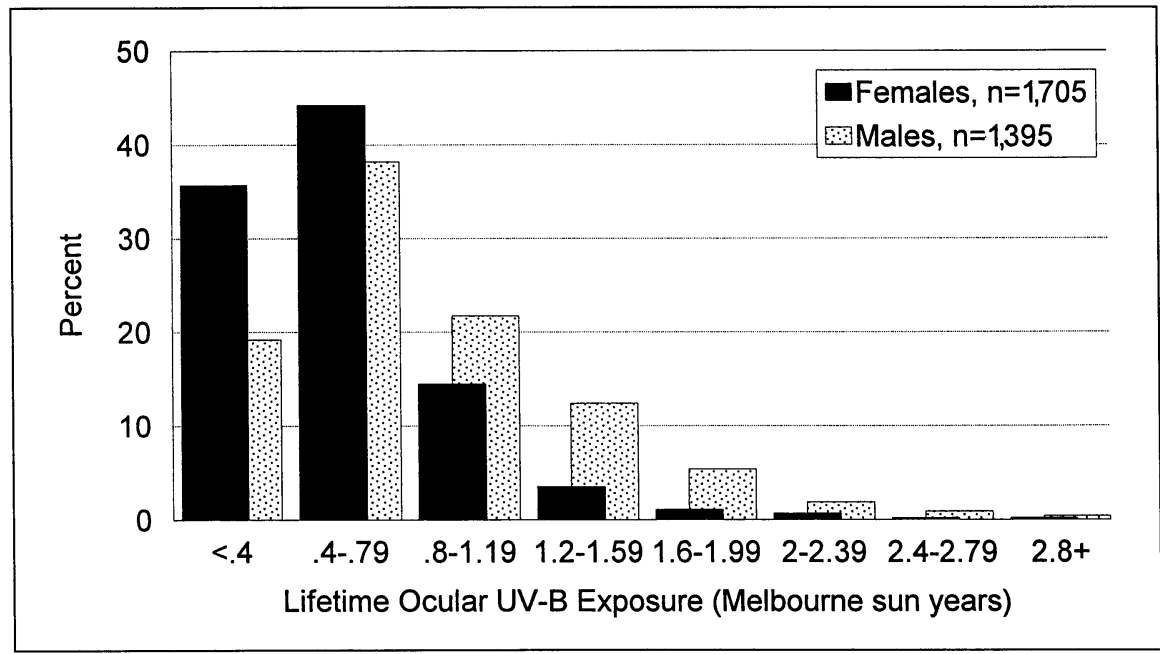

Fig. 1. Gender-specific distribution of lifetime ocular UV-B exposure in the Melbourne Visual Impairment Project.

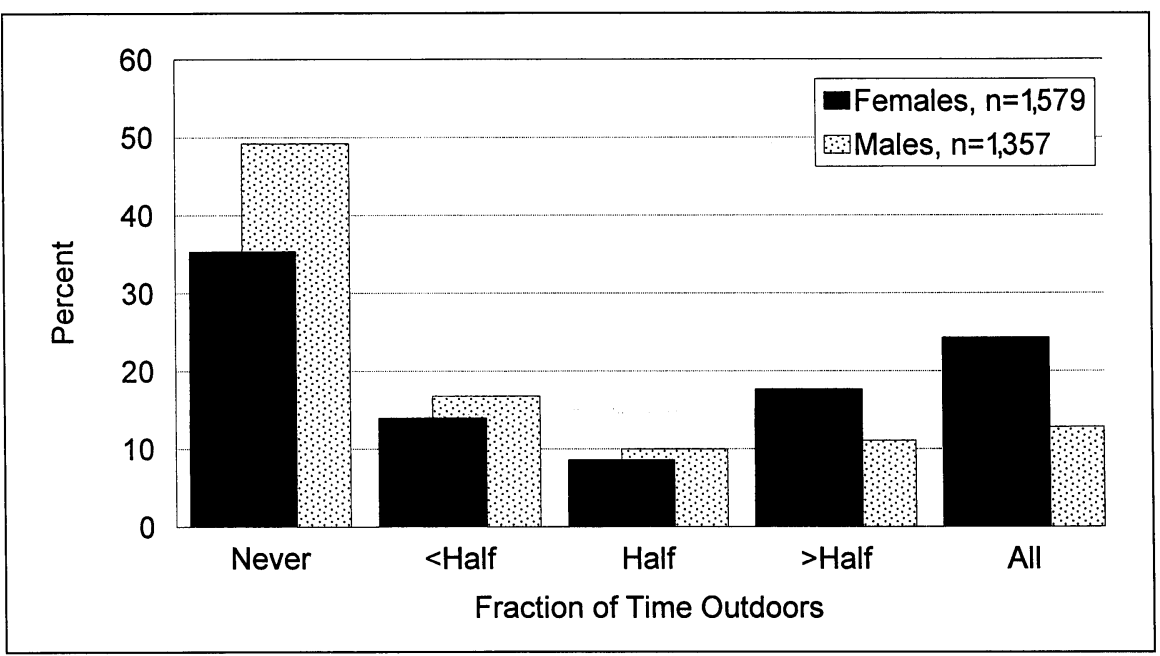

Fig. 2. Gender-specific distribution of current hat use while in the sun.

Current use of ocular protection while outdoors also varied significantly by gender. Females were more likely to wear a hat $\left(\chi^{2}=46.79, p<0.001\right)$ (fig. 2), whereas males were more likely to wear sunglasses $\left(\chi^{2}=111.29, \mathrm{p}<0.001\right)$. However, $42 \%$ of the entire cohort reported never wearing sunglasses (fig. 3 ). 


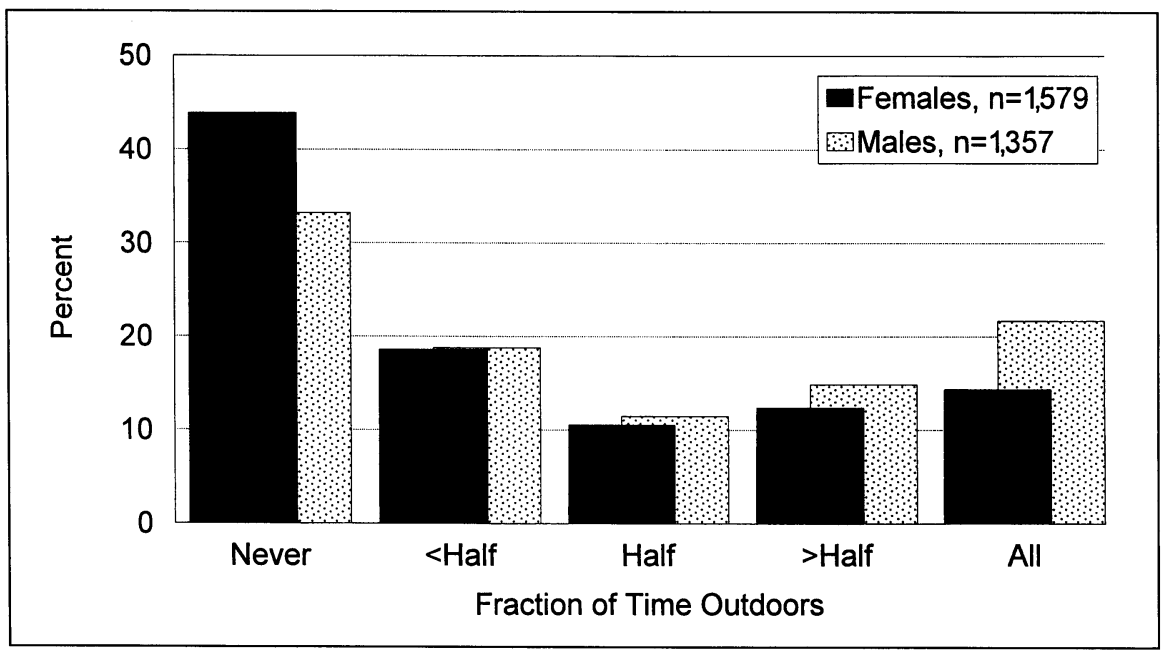

Fig. 3. Gender-specific distribution of current sunglass use while in the sun.

\section{Discussion}

In summary, we developed a questionnaire and model to quantify lifetime personal ocular UV-B exposure in the context of large epidemiologic studies. It is especially important to quantify the contribution of ocular UV-B exposure to the development and progression of eye diseases now because of the changes in the protective atmospheric ozone layer. The implications for public health and medical costs in the future are enormous [2].

Sliney [12] has suggested that the ocular ambient exposure ratio used in current models requires modification due to geometric factors such as eyebrows and the protective squint mechanism and Duncan et al. [13] have suggested that ocular ambient exposure ratios may vary by occupation. The present model will easily accommodate refined attenuation factors when they become available.

In conclusion, it is essential to gather individual information about UVB exposure and ocular protection to quantify lifetime personal ocular UV-B exposure and avoid the ecological fallacy. The current questionnaire and model are useful for the collection of this information in large epidemiologic studies.

\section{Acknowledgements}

The Melbourne Visual Impairment Project is supported in part by grants from the Victorian Health Promotion Foundation, the National Health and Medical Research Council and the Ansell Ophthalmology Foundation. The authors gratefully acknowledge the advice 
of Dr. Charles Guest in the development of the sunlight questionnaire and the consultation of Mr. Matthew Lee in the computer programming for analysis.

\section{References}

1 Dolin PJ, Johnson GJ: Solar ultraviolet radiation and ocular disease: A review of the epidemiological and experimental evidence. Ophthalmic Epidemiol 1994;1:155-164.

2 The Effects of Solar Radiation on the Eye. Geneva, World Health Organization, 1994, pp 3-22.

3 Morgenstern H: Uses of ecologic analysis in epidemiologic research. Am J Publ Health 1982;72: 1336-1344.

4 Taylor HR: Assessment of personal ocular UV-B exposure. Invest Ophthalmol Vis Sci 1994;35: 1326.

5 Taylor HR, Muñoz B, Rosenthal FS, West S: An abbreviated assessment of ocular exposure to ultraviolet radiation. Aust NZ J Ophthalmol 1992;20:219-223.

6 Rosenthal FS, Safran M, Taylor HR: The ocular dose of ultraviolet radiation from sunlight exposure. Photochem Photobiol 1985;42:163-171.

7 Rosenthal FS, Bakalian AE, Taylor HR: The effect of prescription eyewear on ocular exposure to ultraviolet radiation. Am J Publ Health 1986;76:1216-1220.

8 Rosenthal FS, Bakalian AE, Lou C, Taylor HR: The effect of sunglasses on ocular exposure to ultraviolet radiation. Am J Publ Health 1988;78:72-74.

9 Rosenthal FS, Phoon C, Bakalian AE, Taylor HR: The ocular dose of ultraviolet radiation to outdoor workers. Invest Ophthalmol Vis Sci 1988;29:649-656.

10 Rosenthal FS, West SK, Muñoz B, Emmett EA, Strickland PT, Taylor HR: Ocular and facial skin exposure to ultraviolet radiation in sunlight: A personal exposure model with application to a worker population. Health Physics 1991;61:77-86.

11 Livingston PM, Carson CA, Stanislavsky YL, Lee SE, Guest SE, Taylor HR: Methods for a population-based study of eye disease: The Melbourne Visual Impairment Project. Ophthalmic Epidemiol 1994;1:139-148.

12 Sliney DH: Epidemiological studies of sunlight and cataract: The critical factor of ultraviolet exposure geometry. Ophthalmic Epidemiol 1994;1:107-119.

13 Duncan DD, Schneider W, West KJ, West S, Rubin GS, Schein OD, Fried L, Zeger SL: Development of personal dosimeters for use in the visible and ultraviolet wavelength region: SEE Project. Invest Ophthalmol Vis Sci 1995;36:S535.

Dr. Cathy McCarty, University of Melbourne, Department of Ophthalmology, Royal Victorian Eye and Ear Hospital, 32 Gisborne Street, East Melbourne, Vic. 3002 (Australia) 


\section{University Library}

\section{- M M I N E R VA A gateway to Melbourne's research publications}

Minerva Access is the Institutional Repository of The University of Melbourne

Author/s:

McCarty, Catherine A.;Lee, Sharon E.;Livingston, Patricia M.;Taylor, Hugh R.

Title:

Assessment of lifetime ocular exposure to UV-B: the Melbourne Visual Impairment Project

Date:

1997

Citation:

McCarty, C. A., Lee, S. E., Livingston, P. M., \& Taylor, H. R. (1997). Assessment of lifetime ocular exposure to UV-B: the Melbourne Visual Impairment Project. Developments in Ophthalmology, v. 27, 9-13.

Publication Status:

Published

Persistent Link:

http://hdl.handle.net/11343/34458 